\title{
CRIANÇAS NA ENGENHARIA DE MINAS
}

\author{
F. C. Nogueira; A. R. Ferreira; C. C. Rodrigues; L. P.F. Lopes; C. A. Pereira \\ Universidade Federal de Ouro Preto \\ franciellenoguera@yahoo.com.br ${ }^{*}$
}

Submetido 02/11/2017 - Aceito 29/11/2017

DOI: $10.15628 /$ holos. 2017.6498

\section{RESUMO}

O projeto há 17 anos integra comunidade acadêmica, professores, alunos e sociedade através de oficinas de arte cantaria e atividades semanais de ensino com crianças. Por ano são selecionados sessenta alunos de escolas públicas de Ouro Preto, com média de idade de onze anos para participarem do projeto. As atividades são ministradas por graduandos dos diversos cursos da Universidade e ocorrem no Departamento de Engenharia de Minas, campus UFOP, as terças e quintas feiras. O projeto tem como objetivo proporcionar um contato das crianças com o mundo da universidade e despertar neles a vontade pela construção do conhecimento. $\mathrm{O}$ projeto oferece também aos participantes: reforço escolar, aulas de leitura, escrita e interpretação, contribuindo para alfabetização e melhoria no desempenho escolar. A interação com os alunos de escolas públicas da região traz à tona os diversos problemas enfrentados na educação brasileira. Os resultados foram: humanização das relações em âmbitos acadêmicos, formação de profissionais com consciência cidadã, melhoria no desempenho escolar das crianças, divulgação do patrimônio material de Ouro Preto.

PALAVRAS-CHAVE: projeto de extensão, cidadania, cultura, educação patrimonial

\section{CHILDREN IN MINING ENGINEERING}

\begin{abstract}
The project for 17 years integrates academic community, teachers, students and society through workshops of stonemansory and weekly activities with children. Per year are selected 60 students of public schools of Ouro Preto, with an average age of 11 years old to participate in the project. The activities are taught by graduates of University courses and occur in mining engineering departament, at UFOP, on Tuesdays and Thursdays. The project aims to provide a children's contact with the University world and awaken in them the desire for knowledge construction. The project also
\end{abstract}

offers participants: school reinforcement classes in reading, writing and interpretation, contributing to children's literacy and improvement in school performance. The interaction with students of public schools in the region brings up the various problems faced in brazilian education. The results were: humanization of relations in academic areas, training of professionals with citizen awareness, improved school performance of children, disclosure of the material heritage of Ouro Preto

KEYWORDS: extension project, citizenship, culture, heritage education 


\section{INTRODUÇÃO}

Rodeada de montanhas e localizada no estado de Minas Gerais, a histórica cidade de Ouro Preto originou-se com a união de diversos garimpos de ouro. Em razão da importância econômica à época e do número de jazidas na região, Vila Rica, como foi chamada foi elevada, em 1720, a capital da Capitania de Minas Gerais.

A cidade conta com características e arquitetura marcante, oriundas dos séculos XVIII, XIV e XX (Silva, Fernandes, Pereira, 2003), que ainda são preservadas assim como boa parte da arquitetura religiosa e civil além das fortes expressões artísticas e seu traçado urbano colonial. Devido a estas características, Ouro Preto foi declarada Monumento Nacional em 1933 e tombada pelo Instituto do Patrimônio Histórico e Artístico Nacional, IPHAN, em 1938. Anos depois, em 1980, foi declarada pela UNESCO como Patrimônio Mundial pela Organização das Nações Unidas para a Educação, a Ciência e a Cultura.

A arte cantaria é parte do conjunto arquitetônico de Ouro Preto e faz-se presente em diversos pontos da cidade. Entende-se por cantaria, a pedra aparelhada geometricamente ou lavrada em formas geométricas, utilizada na construção de edifícios, além de faixadas, chafarizes, pontes e até mesmo cantos de casas (Pereira, Fernandes, Silva, Oliveira, Netto 2004). As rochas utilizadas são esteatito, conhecida como pedra-sabão e o quartzito.

A rocha era trabalhada e transformada em arte pelos mestres canteiros, e o conhecimento passado de geração em geração (Luz, Balarezo, Pereira 2003). As mudanças na sociedade fizeram com que o ofício de canteiro fosse de pouco a pouco se dispersando. E embora Ouro Preto traga ainda muitos traços da arquitetura colonial, não se pode deixar de ressaltar que ações humanas de degradação, pichação e vandalismo têm atingido partes históricas da cidade, colocando em risco a preservação histórica da cidade.

Falta, por parte da população, sensibilização sobre a importância e valor da história encontrada na cidade e os registros do passado em suas vidas. As pessoas não se sentem parte desta história somente por ela não ter sido construída por elas, mas a construção de uma relação de pertencimento entre as novas gerações e o patrimônio da cidade mostra-se necessária, visto que elas poderiam, de forma mais prazerosa sentir-se parte da história deixada por seus antepassados (Silva et al, 2003).

\subsection{Contexto entre universidade, cidade e projetos de extensão}

A atividade de extensão representa um elo entre o social e o institucional (ensino e pesquisa) tendo como característica a difusão de conhecimento através de reflexões de temas comuns à comunidade, trabalhando em pontos de interseção entre a universidade, necessidades políticas, econômicas e sociais. Tal atividade deve ser um elo de equilíbrio entre demandas sociais e trabalho acadêmico (Política Nacional de Extensão, 2012).

As atividades de extensão na Universidade Federal de Ouro Preto tiveram início somente onze anos após a fundação da Instituição. No ano de 1980, o programa "Escritório-Piloto dos Estudantes" desenvolvido por alunos dos cursos de engenharia, ajudou na construção de casas 
para famílias afetadas pela forte chuva que atingiu Ouro Preto em 1979. Já no ano de 2013, a instituição contou com 140 projetos de extensão (Pereira, Carvalho, Nogueira, 2014)

Visando manter viva a arte cantaria e desenvolver a conscientização patrimonial dos cidadãos de Ouro Preto, criou-se o projeto Cantaria, que desde 2000 vêm integrando comunidade acadêmica e sociedade através de oficinas e atividades semanais de ensino com crianças da cidade (Carvalho, Lopes, Pereira, Silva, Silva, Silva, Pereira 2009).

\section{METODOLOGIA}

O projeto "Educação e Arte para Crianças" recebe por ano 60 crianças com idade média de onze anos da rede pública de ensino de Ouro Preto. As aulas são oferecidas no turno da manhã e da tarde de acordo com o horário escolar de cada criança. Para garantir o deslocamento das crianças e responsáveis até a universidade, são disponibilizados vales transportes de ida e volta.

Os temas discutidos nos encontros abrangeram diferentes áreas do conhecimento, como educação patrimonial, informática, história, português, matemática, biologia, química, artes, cultura, lógica, lazer, meio ambiente e atualidades. Destaca-se nesta linha do projeto a multidisciplinaridade das atividades desenvolvidas.

Os monitores do projeto são estudantes de diferentes cursos de graduação, tais como: História, Engenharias, Letras, Educação Física, Artes Cênicas, Farmácia, Arquitetura, Ciência e Tecnologia de Alimentos. Além disso, os alunos são de diferentes períodos, o que facilita a troca de experiências e conhecimentos entre colaboradores que, muitas vezes, encaram a atividade extensionista com visões distintas.

O trabalho é constituído de duas fases distintas. Na primeira, é feita a seleção dos monitores do projeto e estruturação das atividades e na segunda ocorre o contato direto com a comunidade. No primeiro instante, os monitores e a coordenação do projeto reúnem-se para avaliação do ano anterior e realização das modificações necessárias para o ano corrente. Nessa etapa, são confeccionados convites destinados à apresentação do projeto para as escolas públicas e elaborados o calendário semestral e os planos de aula. Durante esse período a troca de conhecimentos professor/aluno e também aluno/aluno é intensa e muito importante para estruturação das atividades.

Em seguida, realizam-se reuniões com as diretoras e professoras das escolas para apresentar a proposta do projeto. A seleção dos alunos do $5^{\circ}$ ano do ensino fundamental fica a critério das escolas. Depois de selecionados os alunos, é marcada uma reunião com os responsáveis das crianças para apresenta-los o projeto e esclarecer suas dúvidas. Nesta reunião, é possível que os participantes apresentassem suas expectativas e adicionem sugestões de conteúdo a ser abordado durante as aulas.

Paralelamente às escolas, o projeto tem como objetivo proporcionar um contato das crianças com o mundo desconhecido da universidade e despertar neles a vontade pela construção do conhecimento. O projeto oferece também aos participantes reforço escolar, aulas de leitura, escrita e interpretação, contribuindo para a alfabetização e melhoria no desempenho escolar. 
As atividades de apropriação cultural são realizadas de acordo com a Tabela 1, seguindo características do projeto expostas por Silva et al (2003):

Tabela 1 - Atividades de educação patrimonial realizadas no projeto

\begin{tabular}{|c|c|c|}
\hline Etapas & Recursos/Atividade & Objetivos \\
\hline Contato & $\begin{array}{l}\text { - Apresentação do tema Cantaria } \\
\text { por meio de curtas palestras, } \\
\text { ferramentas e banners (contendo } \\
\text { imagens de monumentos, que } \\
\text { privilegiem a cantaria em relação } \\
\text { ao monumento). } \\
\text {-Divisão da sala em dois grupos, } \\
\text { sem critérios de gênero, para } \\
\text { realizar jogos de identificação dos } \\
\text { objetos representados nas } \\
\text { imagens e perguntas sobre a } \\
\text { cantaria e o patrimônio. } \\
\text { Premiando de forma diferenciada } \\
\text { os dois grupos. }\end{array}$ & $\begin{array}{l}\text {-Trabalhar o tema e a } \\
\text { importância do patrimônio } \\
\text { cultural. } \\
\text { - Capacidade de identificação } \\
\text { visual do tema e dos objetos } \\
\text { contidos nos banners. } \\
\text { - Estimular um ambiente } \\
\text { saudável de competição, sem } \\
\text { distinção de gênero e o } \\
\text { estigma de vencedores e } \\
\text { vencidos. }\end{array}$ \\
\hline Estimulação & $\begin{array}{l}\text { - Visita orientada pelos bolsistas e } \\
\text { oficiais canteiros a Oficina da } \\
\text { Escola de Cantaria. } \\
\text {-Noções básicas de segurança, } \\
\text { apresentação dos tipos de } \\
\text { ferramentas usadas e as rochas } \\
\text { existentes na região. } \\
\text {-É hora de brincar: cada criança } \\
\text { recebe óculos de proteção, uma } \\
\text { ferramenta e, com mais quatro } \\
\text { colegas, escolhem um tipo de } \\
\text { rocha para esculpirem o que bem } \\
\text { entenderem, tudo sob orientação } \\
\text { de um bolsista ou oficial, para } \\
\text { cada grupo de cinco crianças }\end{array}$ & $\begin{array}{l}\text {-Fixação das informações. } \\
\text {-Vivenciar o contato com os } \\
\text { materiais, ferramentas e a } \\
\text { prática do ofício. } \\
\text {-Aprender a se relacionar com } \\
\text { as formas tradicionais de saber } \\
\text { e fazer. } \\
\text {-Valorização do trabalho do } \\
\text { artesão. } \\
\text {-Trabalhar em conjunto com a } \\
\text { equipe. }\end{array}$ \\
\hline Percepção & $\begin{array}{l}\text {-Realização de um passeio, } \\
\text { previamente estabelecido, em } \\
\text { determinadas ruas do centro } \\
\text { histórico ou em local próximo da } \\
\text { escola ou bairro, mas desde que } \\
\text { contemple a cantaria. }\end{array}$ & $\begin{array}{l}\text {-Identificação dos objetos, sua } \\
\text { função e significado no espaço } \\
\text { urbano. } \\
\text {-Desenvolvimento da } \\
\text { percepção visual e simbólica }\end{array}$ \\
\hline
\end{tabular}




\begin{tabular}{|c|c|c|}
\hline & $\begin{array}{l}\text {-Exploração dos locais visitados, } \\
\text { complementando informações } \\
\text { e/ou levantando } \\
\text { questionamentos a respeito das } \\
\text { condições de preservação do } \\
\text { patrimônio. }\end{array}$ & $\begin{array}{l}\text { da cantaria nos bens. } \\
\text {-Reapropriação desses locais, } \\
\text { enquanto espaços de } \\
\text { fortalecimento da identidade } \\
\text { cultural individual e coletiva }\end{array}$ \\
\hline Apropriação & $\begin{array}{l}\text {-Elaboração de um roteiro da } \\
\text { cantaria em Ouro Preto, segundo } \\
\text { os critérios definidos pela turma. } \\
\text { Pode-se, como alternativa ao } \\
\text { roteiro, apresentar textos } \\
\text { literários, colagens, pinturas } \\
\text { desenhos, música, escultura, peça } \\
\text { teatral e vídeos. } \\
\text {-Divulgação dos trabalhos nas } \\
\text { escolas para a comunidade e a } \\
\text { realização de um evento para } \\
\text { premiação das turmas que } \\
\text { participaram. }\end{array}$ & $\begin{array}{l}\text {-Envolvimento afetivo com o } \\
\text { uso, conservação da } \\
\text { preservação do patrimônio } \\
\text { cultural apropriado. } \\
\text {-Desenvolvimento } \\
\text { capacidade de auto-expressão. } \\
\text {-Participação dos pais e } \\
\text { comunidade no processo de } \\
\text { valorização do bem cultural. } \\
\text {-Envolvimento da comunidade } \\
\text { no processo de valorização e } \\
\text { preservação do patrimônio } \\
\text { cultural local, estabelecendo } \\
\text { um efeito }\end{array}$ \\
\hline
\end{tabular}

Nas aulas de história trata-se da história de Ouro Preto, sua importância no cenário nacional e mundial, as características da arte cantaria, e também se aborda a questão da apropriação patrimonial, visto que apesar de viverem em uma cidade rica de histórias nem todas as crianças se sentem parte daquela importante história. Busca-se resgatar através do contato das crianças com suas famílias histórias antigas e hábitos que os avós e antepassados tinham, salientando a importância dessa assimilação cultural.

Através das aulas interativas de literatura tenta despertar o hábito da leitura, ampliando o vocabulário das crianças e buscando melhorias nas capacidades de fala em público, ao mesmo tempo em que aumenta-se a gama de palavras conhecidas e a capacidade de interpretar textos de uma forma mais crítica, que não somente o modelo leitura-repetição.

São ministradas aulas sobre ecologia, aquecimento global e a importância do meioambiente. Para ampliar a visão dos alunos sobre o tema, mescla-se atividades em sala de aula e também atividades de campo, onde os mesmos podem experimentar novas maneiras de aprendizado.

As aulas de língua estrangeira são preparadas pensando em introduzir as crianças à uma segunda língua e também a cultura por trás do idioma. Elas puderam aproximar-se mais deste assunto novo para alguns, principalmente por não ser tão trabalhado nas escolas públicas do país deixando o Brasil atrás de outros países que já trabalham o segundo idioma desde a educação infantil. São trabalhadas palavras recorrentes do dia-a-dia, vocabulário básico além das influências das palavras estrangeiras na língua portuguesa. 
Atividades envolvendo conscientização política e noções de política foram também desenvolvidas afim de apresentar o sistema de governo em que vivemos, as diferentes formas de governo existentes e também a função dos cargos existentes na política brasileira.

\section{RESULTADOS E DISCUSSÕES}

O Plano Nacional para a Educação (PNE) decênio 2011/2020, é uma lei ordinária brasileira que terá vigência de dez anos a partir de 26/06/2014. O plano conta com 20 metas estabelecidas nos âmbitos de investimento, qualificação de professores, educação básica, democratização do ensino superior, educação técnica e elevação da escolaridade entre outras (Brasil, 2010).

A lei apresenta cinco metas diretamente relacionadas com o público atendido no projeto Educação e arte para crianças. Sendo relacionadas diretamente ao ensino fundamental, alfabetização e aprendizado adequado na idade certa. Destas cinco, destacam-se três que são intimamente relacionadas à faixa etária das crianças do projeto. São elas:

- Universalizar o ensino fundamental de nove anos para toda a população de seis a 14 anos e garantir que pelo menos $95 \%$ dos alunos concluam essa etapa na idade recomendada, até o último ano de vigência deste PNE;

-Alfabetizar todas as crianças, no máximo, até os oito anos de idade, durante os primeiros cinco anos de vigência do plano; no máximo, até os sete anos de idade, do sexto ao nono ano de vigência do plano; e até o final dos seis anos de idade, a partir do décimo ano de vigência do plano;

-Fomentar a qualidade da educação básica em todas as etapas e modalidades, com melhoria do fluxo escolar e da aprendizagem visando aumentar as notas do Ideb (Índice de desenvolvimento da educação básica) para 6,0 nos anos iniciais do ensino fundamental e para 5,5 nos anos finais.

O Projeto Cantaria através das aulas de leitura, escrita e interpretação, contribui para alfabetização e melhoria no desempenho escolar. Levando-se em conta que o projeto trabalha com uma população carente da cidade o projeto possibilita aos participantes contato com computadores, com internet e outros recursos que nem todos têm acesso em casa, realizando uma inclusão e um contato maior com atividades não rotineiras para muitos.

As iniciativas e ações dentro do projeto corroboram e contribuem para o alcance destas três metas estabelecidas dentro do plano. Visto que proporcionam às crianças maior tempo em contato com literatura, mais tempo destinado à educação e ajuda crianças com dificuldades escolares através do reforço oferecido.

Além disso, a interação com os alunos de escolas públicas da região traz à tona os diversos problemas enfrentados pelos educadores e famílias. O desafio está no oferecimento de um ensino de qualidade que seja também inclusivo e desperte a busca pelo conhecimento por parte dos alunos, criando uma ponte entre a transmissão do conhecimento pelo professor e a construção do conhecimento pelo aluno.

Tal interação expõe ainda outra dificuldade enfrentada na educação brasileira, mas desta vez pelos nossos universitários. A necessidade de humanizar as relações em âmbitos acadêmicos 
e formar profissionais cidadãos, cada vez mais amplos e com boa capacidade de se relacionar e propagar o universo com o qual ele teve contato dentro de sua formação.

\section{CONCLUSÃO}

O projeto Cantaria através de suas ações de leitura, escrita e interpretação de textos contribui para alfabetização e melhoria do desempenho escolar das crianças participantes e através da educação patrimonial contribui para conservação do património de material e imaterial da cidade histórica de Ouro Preto.

Em uma perspectiva da extensão, este projeto tem estreitado os laços entre a Universidade e uma parcela importante da sociedade, incentivando o ingresso de crianças e jovens no ensino superior.

\section{REFERÊNCIAS}

Carvalho, C. P. S., Lopes, M., Pereira, F. L., Silva, T. M., Silva, P. C., Silva, F. G., Pereira, C. A. (2009). Educação e Extensão Universitária para crianças. X Congresso Iberoamericano de Extension Universitária. Havana.

Fórum de Pró-Reitores de extensão das universidades brasileiras Política Nacional de Extensão Universitária. (2012). Disponível em: http://www.renex.org.br/documentos/2012-07-13Politica-Nacional-de-Extensao.pdf acesso em: 12 de março de 2015.

Luz, J. A. M., Balarezo, F. J. M., Pereira, C. A. (2003) Emprego de Argamassa expansiva e termoconsolidação de peças em cantaria. REM: R. Esc. Minas, Ouro Preto, 56(3): 161-167, jul-set.

Pereira, C. A., Fernandes S. M. S., Silva, F. G., Oliveira, H., Netto A. J., (2004). Revisitando Ouro Preto através da Cantaria. Anais do $2^{\circ}$ Congresso Brasileiro de Extensão Universitária, Belo Horizonte.

Pereira, C. A., Carvalho, N. L. N., Nogueira, F. C. (2014). A evolução do Projetos de Extensão na Universidade Federal de Ouro Preto. Congresso Brasileiro de Educação em Engenharia. Poços de Caldas.

Silva, F. G., Oliveira, H., Fernandes, S. M. S., Pereira, C.A. (2003). Educação Patrimonial Através da Cantaria em Ouro Preto. Congresso Internacional de Arquitetura Vernácula. 